\title{
Relative age within school year and the diagnosis of ADHD: a nationwide population-based study
}

Kapil Sayal, Roshan Chudal, Susanna Hinkka-Yli-Salomäki, Petteri Joelsson, Andre Sourander

Division of Psychiatry and Applied Psychology, School of Medicine, University of Nottingham, Nottingham, UK (Prof Kapil Sayal, PhD);

CANDAL (Centre for ADHD and Neurodevelopmental Disorders across the Lifespan), Institute of Mental Health, Nottingham, UK (Prof Kapil Sayal, PhD);

Department of Child Psychiatry, University of Turku, Turku, Finland (Dr Roshan Chudal, PhD; Dr. Susanna Hinkka-Yli-Salomäki, PhLic; Dr Petteri Joelsson, MD, Prof Andre Sourander, PhD);

Department of Child Psychiatry, Turku University Hospital, Turku, Finland (Dr Roshan Chudal, PhD; Dr. Susanna Hinkka-Yli-Salomäki, PhLic; Dr Petteri Joelsson, MD, Prof Andre Sourander, PhD)

Address correspondence to: Kapil Sayal, Division of Psychiatry \& Applied Psychology, School of Medicine, University of Nottingham, Queen's Medical Centre, Nottingham, NG7 2UH, UK, [kapil.sayal@nottingham.ac.uk],

+44 1158230264 


\section{ABSTRACT}

\section{Background}

There are mixed findings on the relationship between ADHD and younger relative age in class. This study examines whether relative age is associated with ADHD diagnosis in a country where treatment prevalence rates are low and whether any such association has changed over time or relates to comorbid disorders.

\section{Methods}

Using nationwide population-based registers, all Finnish children born between 1991 and 2004 who were diagnosed with ADHD from age 7 years onwards (school starting age), between 1998 and 2011, were identified $(n=6136)$. Incidence ratios (IRs) were used to examine the inter-relationships between relative age, actual age at ADHD diagnosis, and year of diagnosis (1998-2003 vs. 2004-2011).

\section{Findings}

The cumulative incidence of ADHD diagnosis was greatest for younger children within the schoolyear - IRs of 1.26 (boys) and 1.31 (girls). The association between relative age and ADHD diagnosis reflected children diagnosed before the age of 10 years. The strength of this association increased during recent years - for 2004-2011, IRs were 1.37 (95\% CI 1.24,1.53) for May-August and 1.64 (95\% CI 1.48,1.81) for September-December compared with January-April births (oldest). The relative age effect was not explained by comorbid disorders.

\section{Interpretation}

In a health service system with low prescribing rates for ADHD, younger relative age is associated with an increased likelihood of receiving a clinical diagnosis of ADHD. This influence has increased in recent years. Teachers, parents and clinicians should take relative age into account when considering the possibility of ADHD in a child or encountering a child with a pre-existing diagnosis.

Funding: Academy of Finland, Finnish Medical Foundation, Orion Pharma Foundation, Finnish Cultural Foundation. 


\section{INTRODUCTION}

Attention-Deficit/Hyperactivity Disorder (ADHD) is characterised by behavioural symptoms involving hyperactivity, impulsivity and inattention that are inappropriate for the child's developmental level and result in functional impairment. ${ }^{1}$ Epidemiological studies suggest that prevalence rates world-wide are fairly uniform, affecting around 5\% of school-aged children, however, there is considerable international variation in rates of clinical diagnosis and treatment. ${ }^{2-5}$ Although this might partially reflect the availability of and access to services, the perceptions and expectations of adults such as teachers and parents also play a role in the awareness and recognition of possible ADHD. ${ }^{6}$ As part of the clinical assessment, information about symptoms and impairment is gathered from these adults and, for school-aged children, their responses may reflect peer referencing against the developmental expectations and abilities of other children within the same class or school-year. However, many countries have a fixed school starting age and date, resulting in a variation of up to 12 months in age between children within the same school-year. In many countries (such as the UK or US), the school starting age is typically the academic year in which the child turns five or six, when ADHD may still be difficult to diagnose. Although immaturity may impact on school readiness at a young age, by the age of 7 years there are likely to be increasing teacher and parent expectations that children are more able to settle and focus at school.

Over a decade ago, findings from the large nationally representative British Child and Adolescent Mental Health Survey (B-CAMHS) highlighted relative age as a risk factor for child mental health problems (Goodman, 2003). ${ }^{7}$ More recently, there has been increasing interest in the contributory role of young relative age within the school-year towards the diagnosis of ADHD. This work is important because of the potential implications for diagnostic practice and educational advice and policies. In particular, epidemiological studies from countries, such as the United States, Canada, 
Iceland and Israel, where prescribing rates for ADHD are relatively high have shown a relative age effect whereby younger children in a school year are more likely to be diagnosed with and treated for ADHD than their peers in the same school year. ${ }^{8-11}$ These findings have led to concern that ADHD might be over-diagnosed or misdiagnosed in these countries. ${ }^{12,13}$ In contrast, there are mixed findings from large-scale studies from Nordic countries (such as Denmark and Sweden) and Taiwan where the prevalence rates of ADHD treatment in children are lower. ${ }^{14-17}$ Hence, it is possible that a relative age effect may partially be an artefact of national patterns in the recognition and treatment of ADHD. There is also a suggestion of changes over time. Although some studies have not found a consistent year-trend pattern, ${ }^{9,17}$ a Danish study suggested changes in the strength of association over time with a relative age effect that was present between 2000-2004 subsequently disappearing and then becoming reversed, ${ }^{15}$ perhaps reflecting an increased awareness amongst parents, teachers and clinicians about the possibility of mislabeling. A particular gap in previous research is that the potential contributory role of common comorbid disorders such as conduct disorder or oppositional defiant disorder (CD/ODD) and specific learning (developmental) disorders (LD) has not been investigated.

We aimed to examine whether a relative age effect exists within a national context traditionally involving low rates of ADHD diagnosis and treatment and, if so, whether this has changed over time. Within the Nordic countries, Finland has the lowest prevalence rates of medication prescribing for ADHD. ${ }^{18}$ This suggests that ADHD diagnosis might be relatively conservative (although clinician and family treatment preferences also influence prescribing decisions). ${ }^{3}$ Using a large populationbased birth cohort in Finland, the present study adds to previous research by investigating ADHD diagnoses made over a 14-year period (1998-2011) to examine whether there is an association between relative age and ADHD and, if so, whether: a) it operates more strongly at the younger end of the school age-range; b) there is a temporal effect and c) comorbid disorders play a role. Based on 
findings from previous research, ${ }^{7,9,11,15-17}$ we hypothesised that any relative age effect would operate more strongly at younger ages and that there would be a relative age effect in the earlier but not the later study time period.

\section{METHODS}

\section{Case identification and registers}

The source population reflects all singleton live births in Finland between $1^{\text {st }}$ January 1991 and $31^{\text {st }}$ December $2004(n=870,695)$. From this sample, the cases were people registered in the Finnish Hospital Discharge Register (FHDR) with a diagnosis of ADHD (International Classification of Diseases (ICD-10) codes: F90.0, F90.1, F90.8 and F90.9) by $31^{\text {st }}$ December, 2011. In Finland, primary school enrollment begins during the calendar year in which a child turns 7 years of age, with the school year starting in mid-August. Therefore, the eldest in a school-year are born in January and the youngest in December (aged 7 years and 7 months; 6 years and 7 months, respectively) i.e. relative age reflects the child's age within their school-year. Given the aim of investigating the influence of relative age after starting school, children diagnosed with ADHD from the age of seven years onwards were included in the study. After excluding children $(n=13)$ with severe or profound mental retardation, this resulted in a total sample of 6136 children with ADHD. The mean age at ADHD diagnosis in the sample was 9.4 years (standard deviation: 2.4; range: 7-19 years).

The study utilised two Finnish Nationwide registers, the FHDR and the Population Register Centre (PRC). The FHDR includes all medical diagnoses given in hospitals in Finland, including inpatient diagnosis from 1969 and outpatient coverage of specialised hospital services since 1998. In Finland, the diagnosis of ADHD is made in outpatient clinics by a specialist and children's healthcare services are available free of charge. The FHDR was used to identify cases with ADHD, the date the register- 
based ADHD diagnosis was given and whether they have been diagnosed with comorbid CD/ODD or LD (see below). The validity of the diagnosis of ADHD in the FHDR has been demonstrated. ${ }^{19}$ The Finnish healthcare system uses the ICD-10 classification as the prevailing diagnostic system, which refers to the term 'hyperkinetic disorder', but for convenience in this article we refer to it as 'ADHD'. The term 'ADHD' for 'hyperkinetic disorder' has also been used in previous Nordic studies that use the ICD classification. ${ }^{16,20,21}$ The PRC is a digital national archive containing basic information on Finnish citizens and permanent residents. Individual data filed in the register contains, for example, name, personal identity code, citizenship, date of birth/death and emigration/immigration (as noted above, both the source population and ADHD cases were children born in Finland). The PRC was used to identify the number of children born in each birth month during the study period. Permission to use data from the national registers was obtained from the data protection authorities and ethical approval for this research was provided by the Ethics Committee of Hospital District of Southwest Finland.

\section{Comorbid disorders}

Initially, all ADHD cases were analysed regardless of comorbidity (see below). Following this, to assess the possible contribution of comorbid disorders, the cases were stratified according to the presence of: a) any lifetime comorbid CD/ODD (ICD codes: F90.1, F91, F92) and b) comorbid LD (ICD codes F80-F83, reflecting specific developmental disorders of speech and language, scholastic skills and/or motor function) if diagnosed before age 7 years - this was done to minimise the possibility of ADHD being conflated with LD (i.e. key adults are already aware of the existing LD diagnosis when considering the possibility of comorbid ADHD).

\section{Statistical analyses}

\section{Cumulative incidence}


Cumulative incidence and the corresponding 95\% confidence intervals (CIs) of ADHD were estimated with a Poisson-regression model, assuming a Poisson error distribution. Initially, the cumulative incidence in the total sample, and separately for boys and girls, of ADHD/1000 births was calculated for each month of birth and also by blocks of four months i.e. January-April, May-August and September-December. The numerator was the number of ADHD cases born in a specific time period and the denominator the total number of children born during the corresponding time frame. Next, to assess whether a possible relative age effect was a function of the presence of a comorbid disorder, the cumulative incidence was estimated for cases with and without comorbid CD/ODD and comorbid LD.

\section{Incidence ratios (IRs)}

First, IRs of ADHD were estimated, separately for boys and girls, for each birth month compared with births in January. Second, to improve the precision of these estimates and better reflect the way in which adults might conceptualise children within a school year (i.e. as one of the eldest or one of the youngest in the class) the IRs among births in the different four-month periods (May-August, September-December) were estimated compared with births in January-April (eldest group). Third, to examine whether any relative age effect was influenced by actual age at diagnosis (with a greater effect at the younger end of the school age-range) or by a temporal pattern, the sample was stratified by ADHD diagnoses made between 1998-2003 and 2004-2011 (these cut-offs reflecting findings from the literature). ${ }^{7,15}$ Within each strata, based on the median age at diagnosis (9 years), the age of ADHD diagnosis was categorised as diagnosed: a) between 7-9 years of age or b) from age 10 onwards. The IRs of ADHD were estimated, comparing the youngest and middle groups, by relative age, with those born during January-April. Children diagnosed between 1998 and 2003, aged 7-9 years at diagnosis were born between 1991-1996 while those aged 10 years or older were born between 1991-1993. Similarly, children diagnosed between 2004 and 2011, aged 7-9 years were born between 1994-2004 and those aged 10 years or older were born between 1991-2001. 
A number of sensitivity analyses were also conducted:

1) As the main analyses restricted the sample to those diagnosed with ADHD from the age of 7 years onwards (potentially missing the very youngest starters), we also included children diagnosed with ADHD from the age of 6 years and 7 months onwards (youngest school-starting age) to assess the impact on the IRs for each birth month.

2) To address the possibility that later-born children, through being followed up for less time (Supplementary Table 1), might have influenced the findings, we restricted the sample to those born between 1991 and 2001 to ensure that everyone was followed up for a uniform period of time (three years i.e. until their $10^{\text {th }}$ birthday).

3) To address the possibility that the approach to investigating the impact of comorbid LD was too restrictive, by only including children diagnosed with an LD before age 7 years, we repeated this analysis after including all children with a lifetime LD diagnosis (i.e. regardless of the age of diagnosis).

Statistical analyses were performed with SAS software (Version 9.4, SAS Institute, Cary, NC, USA).

\section{RESULTS}

Table 1 shows the ADHD IRs per 1000 births for each birth month among boys and girls. Compared with births in January (reference category), the IRs for ADHD diagnosis among those born later in the year were generally higher. Among boys, the IRs increased from 1.19-fold (95\% CI: 1.04,1.37; $\mathrm{p}=0.014)$ for those born in July to 1.45 -fold $(95 \%$ CI: $1.26,1.66$; $\mathrm{p}<0.0001)$ for births in November. Among girls, increased IRs were observed among those born in the last three months i.e. October to December. The highest IR $(1.59,95 \%$ CI: 1.15,2.17; $\mathrm{p}=0.0050)$ was among girls born in October. Figure 1 provides a visual presentation of the cumulative incidence of ADHD among boys and girls born in each month. 
Table 2 shows the IRs of ADHD among births in different birth periods (January-April, May-August, September-December). Among boys born between September to December, the IR increased 1.26fold (95\% CI: 1.18,1.35; p<0.0001) compared with those born during January to April. The corresponding IR among girls was 1.31 (95\% CI: 1.12,1.54; $\mathrm{p}=0.0070)$.

\section{Table 2 about here}

Table 3 shows that, amongst children who received a diagnosis of ADHD between the ages of 7-9 years, there was an effect of relative age. In contrast, there was no increase in IR among children diagnosed at a later age (10 years or older). This effect was seen in both cohorts of year of ADHD diagnosis (1998-2003 and 2004-2011) and, contrary to the hypothesised direction, the relative age effect was more prominent among those diagnosed from 2004 onwards compared with those diagnosed in the earlier time period (1998-2003).

Table 3 about here

In terms of the sensitivity analyses, when expanding the sample to include children diagnosed from age 6 years and 7 months onwards (Supplementary Table 2) and also when restricting the sample to enable a uniform period of 3 years follow-up, the pattern of findings was similar. In the latter analyses, compared with the main findings reported in Table 1, there was an increase in the magnitude of the incidence ratios (Supplementary Table 3).

\section{Comorbid Disorders}

Figure 2 (and Supplementary Table 4) show the cumulative incidence of ADHD by birth month among children with and without a comorbid CD/ODD. Among boys who did not have a comorbid 
$\mathrm{CD} / \mathrm{ODD}$, there was a pattern of an increased cumulative incidence of ADHD diagnosis amongst those born later in the year (with the highest proportion observed among those born in November). Among boys with comorbid CD/ODD (27\% of boys), the cumulative incidence of ADHD was greatest for those born between September and December, peaking among births in November i.e. a relative age effect was observed regardless of whether comorbid CD/ODD was present. For girls, small numbers limit conclusions. The cumulative incidence among children with and without LD is shown in Figure 3 (and Supplementary Table 5). The highest cumulative incidence of ADHD was seen among boys without LD, peaking among births in November. For both boys with LD, and for girls, small numbers limit conclusions. The sensitivity analysis including all children with a lifetime LD diagnosis shows that, for boys, there is a relative age effect regardless of whether comorbid LD was present (Supplementary Table 6). For girls, small numbers limit conclusions with no consistent evidence of a relative age effect. Collectively, these findings suggest that any observed relative age effect was not explained by whether comorbid CD/ODD or LD was present.

Figures 2 \& 3 about here

\section{DISCUSSION}

The findings from this study contribute to the literature by demonstrating an association between younger relative age and the diagnosis of $\mathrm{ADHD}$ within a national healthcare context where prescribing rates for ADHD are low compared with other Western countries as well as the epidemiological prevalence of ADHD. ${ }^{3}$ Although this study confirms a relative age effect, there have been mixed findings from other countries with low prescribing rates. ${ }^{14-17}$ It is possible that this discrepancy reflects our specific focus on the receipt of ADHD diagnosis whereas studies from 
Nordic countries which did not find a consistent relative age effect used medication data as the ADHD outcome. ${ }^{14,15}$ In both boys and girls, we found a greater cumulative incidence of clinically diagnosed ADHD amongst younger children within the school-year. There appeared to be a dose-response relationship in that, compared with January-April births, the strength of association with relative age was greater, in turn, for children born during May-August and September-December. As hypothesised, we demonstrated that the relative age effect was influenced by actual child age, particularly affecting the youngest children (aged 7-9 years) in this sample. This suggests that relative age has a greater impact on clinical diagnosis at younger school-attending ages and might be interpreted as a marker of neuro-developmental immaturity. Contrary to our hypothesis and previous research which focused on medication data as the ADHD outcome, ${ }^{15}$ our findings also revealed a temporal pattern with the strength of the association involving relative age increasing in the more recent time period under study. This research spans a 14-year time period during which, internationally, the awareness and clinical recognition of ADHD has increased considerably. 3,4

The observed relative age effect was specific to ADHD and was not influenced by the presence of comorbid disorders (CD/ODD or LD) i.e. the association was not an artefact of whether these comorbid disorders were present. Where there was a comorbid LD diagnosis at a young age, although conclusions are limited by small numbers, it is possible that key adults take this into account when considering the possibility of ADHD. Furthermore, when lifetime comorbid LD was considered, the observed relative age effect (in boys) was not influenced by comorbidity. The finding that there was a relative age effect influencing ADHD diagnosis regardless of whether CD/ODD was present contrasts with comorbidity effects highlighted in previous aetiological research using data from this register which, for example, has demonstrated a stronger association with prenatal maternal smoking among children with ADHD and comorbid CD/ODD. ${ }^{21}$ 
Methodologically, this study has a number of significant strengths. First, the use of a populationbased register enabled a focus on the receipt of a diagnosis of ADHD rather than relying on prescription data. Some previous studies ${ }^{10,11,14}$ only utilised medication prescription data and not all children who receive a diagnosis of ADHD are prescribed medication because of family or clinician preferences. Second, the nationwide coverage of the two registers enabled a nationally representative study involving a large sample size in a country where healthcare is free at the point of delivery with no regional differences or socio-economic barriers in terms of access to and availability of publicly funded healthcare and education services. Third, the study was able to assess temporal patterns in the diagnosis of ADHD over a 14-year period. Fourth, in terms of the analyses, we were able to investigate whether the presence of comorbid ODD/CD or LD influenced the findings. Fifth, the sensitivity analyses highlighted that the findings from the main analyses were robust to a number of assumptions and may have reflected an underestimate of the magnitude of the association. Furthermore, as part of the month-by-month comparison of the cumulative incidence, the direct comparison of December against January suggests that a season of birth explanation for the findings is extremely unlikely.

The study also has some limitations. First, we did not have information on whether any relatively young children were educationally held back a year and therefore potentially misclassified in the analyses i.e. although actually the oldest in their year group, they would be misclassified as being one of the youngest. However, this possibility of exposure misclassification may have reduced the ability of this study to demonstrate a relative age effect. The possibility of some flexibility in school-starting dates might explain why the IRs for December-born children (the relatively youngest) were slightly lower than those for children born in October and November. Second, by relying on clinical diagnosis of ADHD as our main outcome measure, this study is unable to disentangle the extent to which relative age is a risk factor for having ADHD, regardless of whether it is clinically recognised. 
However, findings from a recent study indicate that parent ratings of relative immaturity compared with peers are associated with ADHD symptoms. ${ }^{22}$ Third, the study relied on register-recorded diagnoses of ADHD and although the FHDR reflects children referred to publicly-funded specialised services which are free at the point of access and captures most children who receive a diagnosis of ADHD, it misses those who were diagnosed in private practice.

Teachers are important adults in considering the possibility that a child might have ADHD, ${ }^{23}$ having initial discussions with parents and facilitating the referral of children to services. With a relative age effect, it is possible that the youngest in the class are more likely to get referred and, conversely, older children in the class with possible ADHD might get missed. Once referred, the next consideration is whether the child meets criteria for ADHD. However, we do not know the extent to which actual neuro-developmental immaturity, regardless of relative age, plays a role in the clinical diagnostic decision-making process. Alternatively, given an age variation of up to 12 months, misattributions by adults of immaturity relative to older children in the same class could be paramount. Although this study is unable to distinguish possible mechanisms underlying the findings, reflecting actual neurodevelopmental immaturity in the child or the misattribution of immaturity by adults, there is more support for the latter possibility as the strength of the association with relative age has increased in recent years. If a relative age effect contributes to a referral and diagnostic bias, it could be speculated that a clinical and education service system that does not account for this may contribute to false positive diagnoses, especially as younger children in the class are also more likely to be at an educational disadvantage, ${ }^{10,24}$ which may be misinterpreted as ADHD-related academic impairment.

\section{Conclusions and Implications}


These findings extend previous research by demonstrating a relative age effect influencing ADHD diagnosis in a country with relatively low prescribing rates for ADHD (0.64\% in 7-15 year olds, $2007)^{18}$ and also by highlighting that the strength of this association has increased in recent years. The association is not contingent on the presence of comorbid CD/ODD or LD. In terms of clinical and educational implications, these findings suggest that key adults (teachers and parents) might interpret behaviour differently of children who are younger than their class-mates. When clinicians ask parents or teachers to provide information about ADHD symptoms or impairment, the informant should be asked to keep the child's relative age in mind. Clinicians who are conducting ADHD assessments or who are treating young people with a pre-existing childhood diagnosis of ADHD should also be mindful of, and perhaps consider recording, the person's relative age in relation to their country's school-starting age and cut-off date. Within classrooms, teachers might consider seating arrangements or composition of small groups that reflect the child's relative age. From a wider education perspective, it is important that a range of options are available and that there is flexibility within the system so that an individualised approach can be offered based on the child's needs and the resources available to the school and family. Depending on what might be best for the individual child, these might include, for example, behavioural approaches through key adults to assist with school readiness and classroom behaviour or offering the possibility of flexibility around schoolstarting dates. However, it may not be straightforward to implement these approaches in practice and evidence for effectiveness is required - the possible benefits or harms associated with different intervention approaches are important research questions which ideally require testing through RCT methodologies and the consideration of a range of outcomes, including educational and wider mental health outcomes. 


\section{Authors' contributions}

KS conceptualised the study, participated in the study design and drafted the initial manuscript. RC designed the study and drafted portions of the initial manuscript. SH-Y-S designed the study and carried out the analyses. PC participated in the study design, carried out the literature search and drafted portions of the initial manuscript. AS designed the study. All authors contributed to the interpretation of the data, critical review and revision of the manuscript, and approved the final manuscript as submitted.

\section{Acknowledgments}

The work reported in the manuscript was funded by grants from the Academy of Finland (Andre Sourander), Orion Pharma Foundation (Roshan Chudal), the Finnish Medical Foundation (Roshan Chudal) and the Finnish Cultural Foundation (Petteri Joelsson).

\section{Declarations of Interest}

The authors have no conflicts of interest relevant to this article to disclose. 


\section{REFERENCES}

1. American Psychiatric Association. Diagnostic and Statistical Manual of mental disorders, 5th edn (DSM-5). Washington DC: APA;2013.

2. Polanczyk GV, Willcutt EG, Salum GA, Kieling C, Rohde LA. ADHD prevalence estimates across three decades: An updated systematic review and meta-regression analysis. Int J Epidemiol. 2014;43:434-442.

3. Sayal K, Prasad V, Daley D, Ford T, Coghill D. ADHD in children and young people: prevalence, care pathways and service provision. Lancet Psychiatry (in press).

4. Hinshaw SP, Scheffler RM, Fulton BD, et al. International variation in treatment procedures for ADHD: social context and recent trends. Psychiatr Serv. 2011;62:459-464.

5. Scheffler RM, Hinshaw SP, Modrek S, Levine P. The global market for ADHD medications. Health Aff (Millwood). 2007;26:450-457.

6. Wright N, Moldavsky M, Schneider J, et al. Pathways to Care for ADHD: A Systematic Review of Barriers and Facilitators. J Child Psychol Psychiatry. 2015;56:598-617.

7. Goodman R, Gledhill J, Ford T. Child psychiatric disorder and relative age within school year: cross sectional survey of large population sample. Br Med J. 2003;327:472.

8. Evans WN, Morrill MS, Parente ST. Measuring inappropriate medical diagnosis and treatment in survey data: The case of ADHD among school-age children. J Health Econ. 2010;29:657-673.

9. Morrow RL, Garland EJ, Wright JM, Maclure M, Taylor S, Dormuth CR. Influence of relative age on diagnosis and treatment of attention-deficit/hyperactivity disorder in children. CMAJ. 2012;184:755-762.

10. Zoëga H, Valdimarsdóttir UA, Hernández-Díaz S. Age, academic performance, and stimulant prescribing for ADHD: a nationwide cohort study. Pediatrics. 2012;130:1012-1018.

11. Hoshen MB, Benis A, Keyes KM, Zoëga H. Stimulant use for ADHD and relative age in class among children in Israel. Pharmacoepidemiol Drug Saf. 2016;25:652-660.

12. Thomas R, Mitchell GK, Batstra L. Attention-deficit/hyperactivity disorder: are we helping or harming? Br Med J. 2013;347:f6172.

13. Coon ER, Quinonez RA, Moyer VA, Schroeder AR. Overdiagnosis: how our compulsion for diagnosis may be harming children. Pediatrics. 2014;134:1013-1023.

14. Dalsgaard S, Humlum MK, Nielsen HS, Simonsen M. Common Danish standards in prescribing medication for children and adolescents with ADHD. Eur Child Adolesc Psychiatry. 2014;23:841844. 
15. Pottegård A, Hallas J, Hernández-Díaz, Zoëga H. Children's relative age in class and use of medication for ADHD: a Danish Nationwide Study. J Child Psychol Psychiatry. 2014;55:12441250.

16. Halldner L, Tillander A, Lundholm C, et al. Relative immaturity and ADHD: findings from nationwide registers, parent- and self-reports. J Child Psychol Psychiatry. 2014;55:897-904.

17. Chen MH, Lan WH, Bai YM, et al. Influence of Relative Age on Diagnosis and Treatment of Attention-Deficit Hyperactivity Disorder in Taiwanese Children. J Pediatr. 2016;172:162-167.e1

18. Zoega H, Furu K, Halldorsson M, Thomsen PH, Sourander A, Martikainen JE. Use of ADHD drugs in the Nordic countries: a population-based comparison study. Acta Psychiatr Scand. 2011;123:360-367.

19. Joelsson P, Chudal R, Gyllenberg D, et al. Demographic Characteristics and Psychiatric Comorbidity of Children and Adolescents Diagnosed with ADHD in Specialized Healthcare. Child Psychiatry Hum Dev. 2016;47:574-582.

20. Chudal R, Joelsson P, Gyllenberg D, et al. Parental age and the risk of attentiondeficit/hyperactivity disorder: a nationwide, population-based cohort study. J Am Acad Child Adolesc Psychiatry. 2015;54:487-494.e1.

21. Joelsson P, Chudal R, Talati A, Suominen A, Brown AS, Sourander A. Prenatal smoking exposure and neuropsychiatric comorbidity of ADHD: a Finnish nationwide population-based cohort study. BMC Psychiatry. 2016;16:306.

22. Brikell I, Kuja-Halkola R, Larsson JO, et al. Relative immaturity in childhood and AttentionDeficit/Hyperactivity Disorder symptoms from childhood to early adulthood: exploring genetic and environmental overlap across development. $J$ Am Acad Child Adolesc Psychiatry. 2016;55:886-95.

23. Sax L, Kautz KJ. Who first suggests the diagnosis of attention-deficit/hyperactivity disorder? Ann Fam Med. 2003;1:171-174.

24. Gledhill J, Ford T, Goodman R. Does season of birth matter? The relationship between age within the school year (season of birth) and educational difficulties amongst a representative general population sample of children and adolescents (aged 5-15) in Great Britain. Research in Education. 2002;68:41-47. 


\section{Figure Titles}

Figure 1: ADHD Cumulative Incidence and 95\% Confidence Interval (CI) / 1000 births by birth month

Figure 2: ADHD Cumulative Incidence and 95\% Confidence Interval (CI) / 1000 births with and without comorbid conduct disorder / oppositional defiant disorder (CD), by birth month, boys and girls

Figure 3: ADHD Cumulative Incidence and 95\% Confidence Interval (CI) / 1000 births with and without comorbid learning disorder (LD), by birth month, boys and girls 
Table 1. ADHD incidence ratio (IR) and 95\% confidence intervals (CI) per 1000 births by month of birth, in boys and girls

\begin{tabular}{|c|c|c|c|c|}
\hline \multirow[b]{2}{*}{ Month of Birth } & \multicolumn{2}{|c|}{ Boys $(n=5204)$} & \multicolumn{2}{|c|}{ Girls (n=932) } \\
\hline & $\begin{array}{l}\text { Cases } \\
\text { n (\%) }\end{array}$ & $\begin{array}{c}\text { IR }(95 \% \mathrm{Cl}) \\
\text { P value }\end{array}$ & $\begin{array}{l}\text { Cases } \\
\text { n (\%) }\end{array}$ & $\begin{array}{c}\text { IR }(95 \% \mathrm{Cl}) \\
\text { P value }\end{array}$ \\
\hline January & 369 (7.1\%) & Reference & $63(6.8 \%)$ & Reference \\
\hline February & 378 (7.3\%) & $\begin{array}{c}1.09(0.95,1.26) \\
p=0.26\end{array}$ & 60 (6.4\%) & $\begin{array}{c}1.01(0.70,1.43) \\
p=0.95\end{array}$ \\
\hline March & 409 (7.9\%) & $\begin{array}{c}1.03(0.89,1.18) \\
p=0.65\end{array}$ & $72(7.7 \%)$ & $\begin{array}{c}1.06(0.75,1.48) \\
p=0.72\end{array}$ \\
\hline April & 379 (7.3\%) & $\begin{array}{c}0.97(0.84,1.12) \\
p=0.77\end{array}$ & $81(8.7 \%)$ & $\begin{array}{c}1.20(0.86,1.66) \\
p=0.25\end{array}$ \\
\hline May & 434 (8.3\%) & $\begin{array}{c}1.12(0.98,1.29) \\
p=0.093\end{array}$ & 69 (7.4\%) & $\begin{array}{c}1.04(0.74,1.46) \\
p=0.80\end{array}$ \\
\hline June & 434 (8.3\%) & $\begin{array}{c}1.15(1.00,1.32) \\
p=0.056\end{array}$ & 79 (8.5\%) & $\begin{array}{c}1.22(0.87,1.70) \\
p=0.25\end{array}$ \\
\hline July & $473(9.1 \%)$ & $\begin{array}{c}1.19(1.04,1.37) \\
p=0.014\end{array}$ & $85(9.1 \%)$ & $\begin{array}{c}1.28(0.92,1.77) \\
p=0.15\end{array}$ \\
\hline August & $482(9.3 \%)$ & $\begin{array}{c}1.27(1.11,1.45) \\
p=0.0011\end{array}$ & $80(8.6 \%)$ & $\begin{array}{c}1.23(0.88,1.70) \\
p=0.24\end{array}$ \\
\hline September & 476 (9.2\%) & $\begin{array}{c}1.27(1.11,1.46) \\
p=0.00070\end{array}$ & $78(8.4 \%)$ & $\begin{array}{c}1.23(0.88,1.71) \\
p=0.24\end{array}$ \\
\hline October & 459 (8.8\%) & $\begin{array}{c}1.30(1.13,1.49) \\
p=0.00050\end{array}$ & $97(10.4 \%)$ & $\begin{array}{c}1.59(1.15,2.17) \\
p=0.0050\end{array}$ \\
\hline November & 483 (9.3\%) & $\begin{array}{c}1.45(1.26,1.66) \\
p<0.0001\end{array}$ & $85(9.1 \%)$ & $\begin{array}{c}1.48(1.07,2.05) \\
p=0.019\end{array}$ \\
\hline December & $428(8.2 \%)$ & $\begin{array}{c}1.24(1.08,1.43) \\
p=0.0028\end{array}$ & 83 (8.9\%) & $\begin{array}{c}1.40(1.01,1.95) \\
p=0.044\end{array}$ \\
\hline
\end{tabular}


Table 2. ADHD incidence ratio (IR) and $95 \%$ confidence intervals (CI) per 1000 births by three groups of relative age, in boys and girls

\begin{tabular}{lcccc}
\hline & \multicolumn{2}{c}{ Boys (n=5204) } & \multicolumn{2}{c}{ Girls (n=932) } \\
\hline Month of Birth & $\begin{array}{c}\text { Cases } \\
\mathbf{n}(\%)\end{array}$ & $\begin{array}{c}\text { IR (95\% CI) } \\
\mathbf{P} \text { value }\end{array}$ & $\begin{array}{c}\text { Cases } \\
\mathbf{n}(\%)\end{array}$ & $\begin{array}{c}\text { IR (95\% Cl) } \\
\mathbf{P} \text { value }\end{array}$ \\
\hline January-April & 1535 & Reference & $276(29.6 \%)$ & Reference \\
May-August & $(29.5 \%)$ & $1.15(1.07,1.23)$ & $313(33.6 \%)$ & $1.10(0.93,1.30)$ \\
& 1823 & $\mathrm{p}<0.0001$ & & $\mathrm{p}=0.23$ \\
September- & $(35.0 \%)$ & & $343(36.8 \%)$ & $1.31(1.12,1.54)$ \\
December & 1846 & $1.26(1.18,1.35)$ & & $\mathrm{p}=0.00070$ \\
& $(35.5 \%)$ & $\mathrm{p}<0.0001$ & & \\
\hline
\end{tabular}


Table 3. ADHD incidence ratio (IR) and $95 \%$ confidence intervals (CI) by year of diagnosis, actual age at first diagnosis, and month of birth

\begin{tabular}{|c|c|c|c|c|c|c|c|c|c|}
\hline \multirow{3}{*}{$\begin{array}{l}\begin{array}{l}\text { Year of } \\
\text { Diagnosis }\end{array} \\
\begin{array}{l}\text { Age at first } \\
\text { diagnosis }\end{array}\end{array}$} & & \multicolumn{4}{|c|}{ 1998-2003 } & \multicolumn{4}{|c|}{ 2004-2011 } \\
\hline & & \multicolumn{2}{|c|}{$7-9$ years } & \multicolumn{2}{|c|}{10 years or more } & \multicolumn{2}{|c|}{$7-9$ years } & \multicolumn{2}{|c|}{10 years or more } \\
\hline & & $\begin{array}{l}\text { Cases } \\
\text { n (\%) }\end{array}$ & $\begin{array}{c}\text { IR }(95 \% \mathrm{Cl}) \\
\text { p value }\end{array}$ & $\begin{array}{l}\text { Cases } \\
\text { n (\%) }\end{array}$ & $\begin{array}{c}\text { IR }(95 \% \mathrm{Cl}) \\
\text { p value }\end{array}$ & $\begin{array}{l}\text { Cases } \\
\text { n (\%) }\end{array}$ & $\begin{array}{c}\text { IR }(95 \% \mathrm{Cl}) \\
\text { p value }\end{array}$ & $\begin{array}{l}\text { Cases } \\
\text { n (\%) }\end{array}$ & $\begin{array}{c}\text { IR (95\% } \mathrm{Cl}) \\
\text { p value }\end{array}$ \\
\hline \multirow{3}{*}{$\begin{array}{l}\text { Month of } \\
\text { Birth }\end{array}$} & January-April & $474(31.8)$ & Reference & $81(36.1)$ & Reference & $590(25.1)$ & Reference & 666 (32.2) & Reference \\
\hline & May-August & $500(33.5)$ & $\begin{array}{l}1.04(0.91,1.17) \\
p=0.57\end{array}$ & 77 (34.3) & $\begin{array}{l}0.93(0.68,1.27) \\
p=0.66\end{array}$ & 843 (35.8) & $\begin{array}{l}1.37(1.24,1.53) \\
p<0.0001\end{array}$ & $716(34.6)$ & $\begin{array}{l}1.05(0.94,1.16) \\
p=0.38\end{array}$ \\
\hline & $\begin{array}{l}\text { September- } \\
\text { December }\end{array}$ & $516(34.6)$ & $\begin{array}{l}1.16(1.03,1.32) \\
p=0.016\end{array}$ & $66(29.5)$ & $\begin{array}{l}0.86(0.62,1.18) \\
p=0.35\end{array}$ & $921(39.1)$ & $\begin{array}{l}1.64(1.48,1.81) \\
p<0.0001\end{array}$ & 686 (33.2) & $\begin{array}{l}1.10(0.99,1.22) \\
p=0.075\end{array}$ \\
\hline
\end{tabular}


Figure 1: ADHD Cumulative Incidence and 95\% Confidence Interval (CI) / 1000 births by birth month

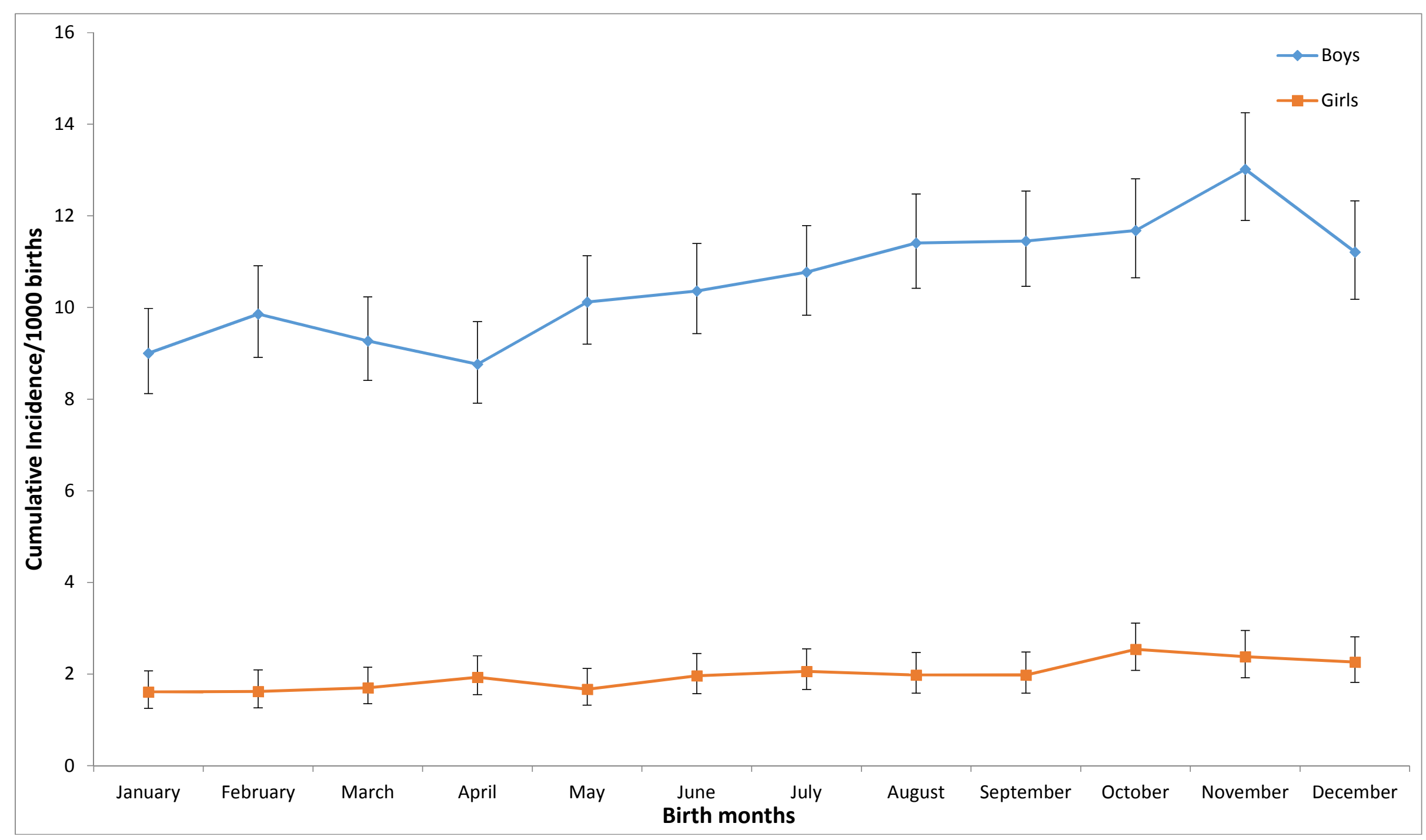


Figure 2: ADHD Cumulative Incidence and 95\% Confidence Interval (CI) / 1000 births with and without comorbid conduct disorder / oppositional defiant disorder (CD), by birth month, boys and girls

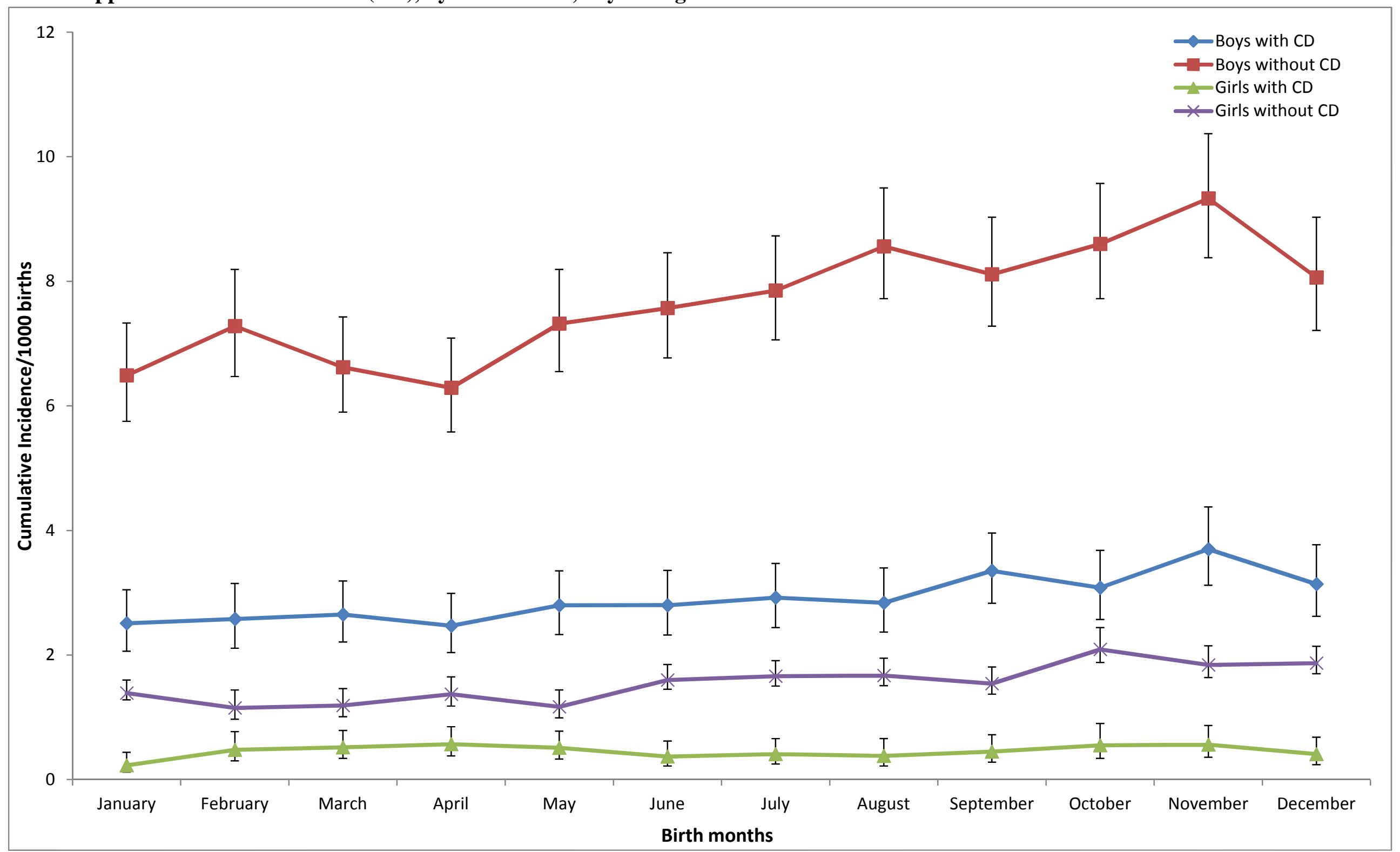


Figure 3: ADHD Cumulative Incidence and 95\% Confidence Interval (CI) / 1000 births with and without comorbid learning disorder (LD), by birth month, boys and girls

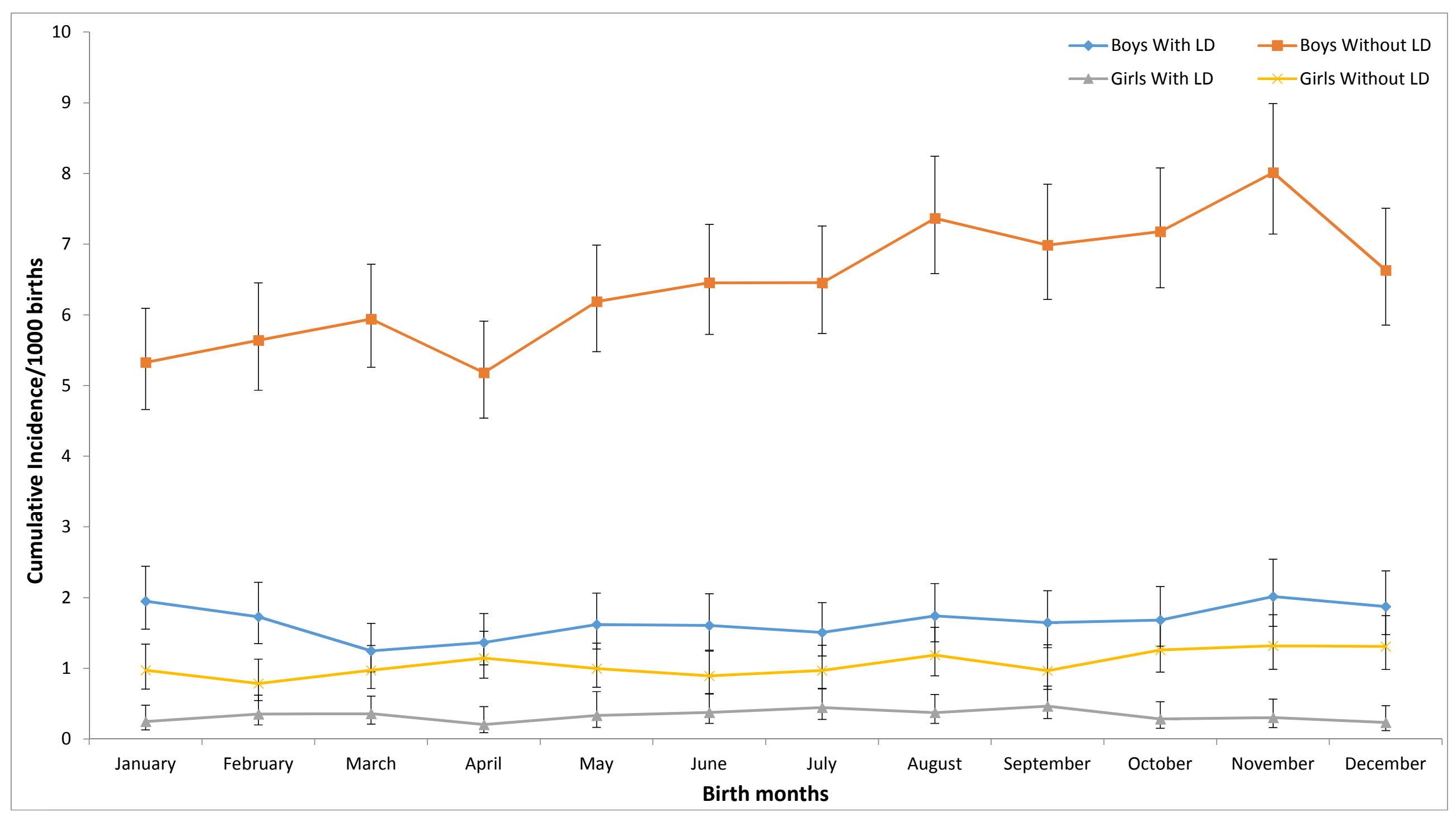

